\title{
Cytokine-induced Meningitis Is Dramatically Attenuated in Mice Deficient in Endothelial Selectins
}

\author{
Tao Tang, ${ }^{\star \ddagger}$ Paul S. Frenette, ${ }^{\star \S}$ Richard O. Hynes,, Denisa D. Wagner, ${ }^{\star \S}$ and Tanya N. Mayadas ${ }^{\star \ddagger}$ \\ $*$ Department of Pathology, ${ }^{\ddagger}$ Brigham and Women’s Hospital, ${ }^{\circledR}$ Center for Blood Research, Harvard Medical School, Boston, \\ Massachusetts 02115; and ${ }^{\|}$Howard Hughes Medical Institute and Center for Cancer Research, Massachusetts Institute of Technology, \\ Boston, Massachusetts 02139
}

\begin{abstract}
Leukocyte accumulation in cerebrospinal fluid and disruption of the blood-brain barrier are central components of meningitis and are associated with a poor prognosis. Genetically engineered deficiencies or functional inhibition of endothelial leukocyte adhesion receptors P-, or P- plus E-selectins, lead to deficits in leukocyte rolling and extravasation. However, their impact on meningeal inflammation has not been tested previously. An acute cytokine-induced meningitis model associated with significant cerebrospinal fluid leukocyte accumulation (averaging 14,000 leukocytes/ $\mu$ l as early as $4 \mathrm{~h}$ ) and blood-brain barrier permeability was developed in adult mice. This model was applied to mice deficient in P-selectin and mice doubly deficient in P- and E-selectins. Partial inhibition of cerebrospinal fluid leukocyte influx and permeability was noted in P-selectin-deficient mice. Mice doubly deficient in P- and E-selectins displayed a near complete inhibition of these parameters. Our results suggest that P- and E-selectins cooperatively contribute to meningitis and that functional blocking of both endothelial selectins in conjunction with antibiotics may provide a therapeutic approach for treatment of bacterial meningitis. (J. Clin. Invest. 1996. 97:2485-2490.) Key words: endothelium • leukocytes - inflammation - cerebrospinal fluid • blood-brain barrier
\end{abstract}

\section{Introduction}

Leukocyte emigration into tissues is a multistep process mediated by leukocyte adhesion receptors. The selectins (P-, E-, and L-selectin) support leukocyte rolling on the vessel wall which is a prerequisite to firm adhesion mediated by $\beta_{2}$ and $\beta_{1}$ integrins on leukocytes (1) and their cognate endothelial receptors, ICAM-1 and VCAM-1, respectively. P- and E-selectins are receptors for neutrophils and mononuclear cells. P-selectin is constitutively present in endothelial cells and platelets (2)

Address correspondence to Tanya N. Mayadas, Vascular Research Division, Department of Pathology, 221 Longwood Ave., Rm. 404, Boston, MA 02115. Phone: 617-278-0194; FAX: 617-732-5933; E-mail: tmayadas@bustoff.bwh.harvard.edu

Received for publication 25 January 1996 and accepted in revised form 18 March 1996.

J. Clin. Invest.

(C) The American Society for Clinical Investigation, Inc.

0021-9738/96/06/2485/06 \$2.00

Volume 97, Number 11, June 1996, 2485-2490 and, along with E-selectin, is dramatically upregulated by cytokines $(3,4)$. Mice genetically engineered with a deficiency in P-selectin (5) and mice doubly deficient in P- and E-selectins generated by two rounds of homologous recombination (6) exhibit deficits in leukocyte rolling and extravasation. E-selectin-deficient mice show no obvious defects in leukocyte extravasation although addition of P-selectin antibody leads to reduced leukocyte influx in thioglycollate-induced peritonitis and delayed-type hypersensitivity reaction (7). Although endothelial selectins have been shown to play a role in diverse disease processes (2), their function in meningitis has not been previously assessed.

Bacterial meningitis is an acute inflammatory process resulting from the invasion of pyogenic bacteria. It often has debilitating neurologic sequelae and a fatality rate between 10 and $40 \%$ despite antibiotic therapy (8). Leukocyte influx in the subarachnoid space and protein accumulation in the cerebrospinal fluid $(\mathrm{CSF})^{1}$ are hallmarks of the disease and antibiotic-induced bacterial death is known to further enhance inflammatory cell influx minutes after administration, causing further tissue damage (9). It is now well recognized that adjuncts to antibiotic therapy that reduce inflammation can reduce mortality (8-10). Inhibition of leukocyte recruitment by antibodies against $\beta_{2}$ integrins, necessary for firm attachment of leukocytes to the endothelium, has been shown to reduce CSF protein accumulation and improve the survival rate of rabbits $(11,12)$.

To determine the role of endothelial selectins in mediating leukocyte and protein accumulation in the CSF, we first developed a murine model of acute cytokine-induced meningitis which was associated with significant inflammatory cell influx and blood-brain barrier (BBB) permeability. Previous reports have described clinical and histopathological manifestations of neonatal murine meningitis $(13,14)$ and pneumococcal meningitis in adult mice (15) and one report demonstrated significant CSF leukocyte influx at $48 \mathrm{~h}$ using Listeria monocytogenes or lymphocytic choriomeningitis virus (16). However, to our knowledge, rapid CSF leukocyte accumulation and injury to the $\mathrm{BBB}$ have not been described previously in adult mice. Meningitis was induced by CSF inoculation of human recombinant IL-1 $\beta$ and TNF $\alpha$ which play key synergistic roles in initiating meningeal inflammation (17-19), and successfully elicit CSF leukocyte influx and BBB injury in rabbits (19) and rats (17). Unlike previous studies where cytokine delivery or infection was through intracisternal injection, we introduced cytokines by lumbar puncture to avoid mechanical disruption of the

1. Abbreviations used in this paper: $\mathrm{BBB}$, blood-brain barrier; CSF, cerebrospinal fluid. 
$\mathrm{BBB}$ and assure reproducible delivery into the CSF. Cytokineinduced meningitis was applied to P-selectin-deficient, $\mathrm{P}$ - and E-selectin doubly deficient mice and their wild-type counterparts and CSF accumulation of leukocytes and protein was measured.

\section{Methods}

\section{Mice}

Experimental mice were 7-12-wk-old males: 19-30 grams, age-matched P-selectin-deficient and wild-type mates (5) and age-matched mice doubly deficient in P- and E-selectin and wild-type mates (6) of a mixed strain (129Sv/C57Bl/6) were used. Animals were bred and maintained in a virus-antibody free facility at the Longwood Medical Center and Center for Blood Research, Harvard Medical School and in a specific-pathogen free animal facility at Center for Cancer Research, Massachusetts Institute of Technology. Generation and maintenance of the selectin-null and wild-type mice used in these studies were as follows. P-selectin-null and wild-type mice were obtained from homozygous matings. Four pairs of the P- and E-selectin-null and corresponding wild-type mice at the 4- and 6-h time point were littermates. The remaining four pairs of animals in these groups and the animals used for the 8- and 24-h time point were generated by homozygous crosses.

\section{Induction of meningitis}

Mice were anesthetized with tribromoethanol (Avertin, $0.3 \mathrm{mg} / \mathrm{gram}$, intraperitoneally) and a superficial dorsal skin incision was made on the lower back of the mouse to visualize the underlying lumbar verte- brae. Human recombinant IL-1 $\beta$ at $1.25 \mathrm{U} / \mathrm{gram}(25 \mathrm{pg} / \mathrm{gram})$ and $\mathrm{TNF} \alpha$ at $4 \mathrm{U} / \mathrm{gram}$ ( $80 \mathrm{pg} / \mathrm{gram}$ ) (generous gifts of Dr. Jof Baker, Genentech Inc., South San Francisco, CA) diluted in $70 \mu$ l of Dulbecco's PBS plus 1\% FCS (vehicle solution) were injected via lumbar puncture at vertebrate level L-1 or L-2. Sham-injected mice received vehicle alone. Murine IL-1 $\beta$ (Genzyme Corp., Cambridge, MA) was administered at doses of $1.25 \mathrm{U} / \mathrm{gram}(18.75 \mathrm{pg} / \mathrm{gram})$ to $62.5 \mathrm{U} / \mathrm{gram}$ (937.5 pg/gram). The incision was sutured. Awake animals showed no outward signs of distress or paralysis and survived $>6 \mathrm{~d}$ after the procedure. To assess BBB permeability to protein, FITC-labeled bovine albumin (50 $\mu \mathrm{g} / \mathrm{gram})$ (Sigma Chemical Co., St. Louis, MO) was injected intravenously 15-20 min after cytokine inoculation. For time points $>6 \mathrm{~h}$, FITC-BSA was injected $4 \mathrm{~h}$ before the experimental time point.

\section{CSF and blood collection}

$2.5,3,4,6,8$, and $24 \mathrm{~h}$ after cytokine inoculation, mice were exsanguinated and peripheral blood was collected. The dura overlying the posterior fossa was exposed surgically, and CSF (typically 8-15 $\mu \mathrm{l}$ ) was collected by careful aspiration into glass capillary pipettes as described by Griffin (20). CSF samples with visible blood contamination were discarded. $4 \mu \mathrm{l}$ of the CSF sample was fixed in $1 \%$ formaldehyde (in PBS) to preserve leukocytes for a hemocytometer count since unfixed leukocytes rapidly aggregated and adhered to the collecting tube, resulting in loss of cells. The rest of the sample was diluted to $25 \mu \mathrm{l}$ with PBS for measurement of BBB permeability or immediately cytospun onto slides and stained with Wright's Giemsa (Harleco, EM Diagnostics Systems, Gibbstown, NJ) to obtain a differential leukocyte count.

Quantitation of CSF and blood leukocytes. Fixed CSF cells were quantitated on a hemocytometer and results were expressed as cells per cubic millimeter $(\mu \mathrm{l})$ in undiluted CSF. Differential leukocyte counts of CSF samples were determined on Wright's Giemsa-stained

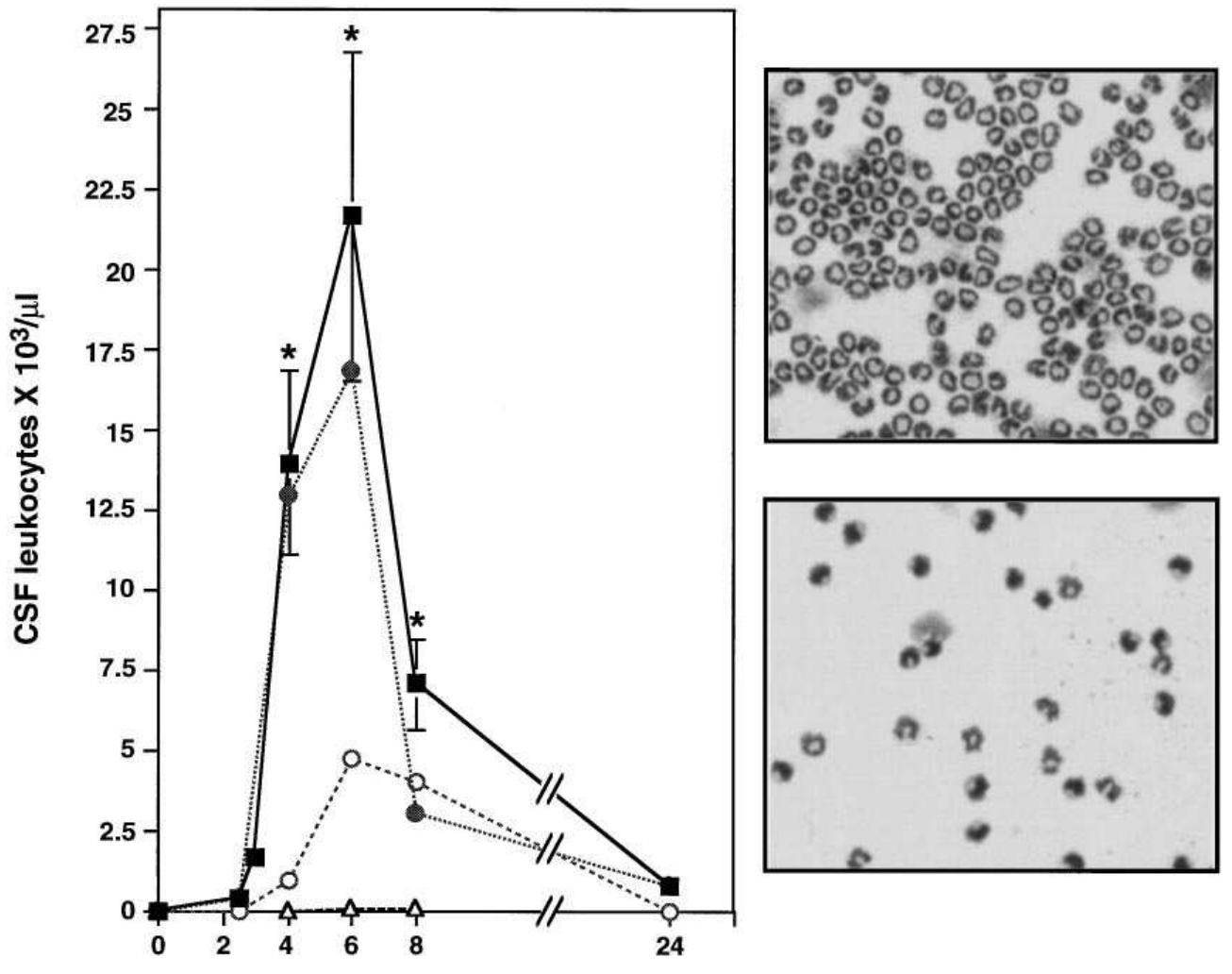

Time (in hours)
Figure 1. Time course of CSF leukocyte accumulation. Wildtype mice $(129 \mathrm{~Sv} / \mathrm{C} 57 \mathrm{BL} / 6$ strain) were inoculated with cytokines or sham-injected. Representative CSF samples collected from the 4- and 8-h time points are shown top right and bottom right, respectively. Cytokines elicited rapid leukocyte accumulation (closed squares) $(n \geq 6$ per time point) which peaked at $6 \mathrm{~h}$ and was significantly above that in sham-injected animals (triangles) ( $n \geq 6$ per time point). Neutrophils (closed circles), which represented $93 \%$ of the cellular infiltrate at $4 \mathrm{~h}$ (top right), peaked at $6 \mathrm{~h}$ whereas mononuclear cells (open circles) were more prominent at $8 \mathrm{~h}$ (bottom right). Data are mean \pm SEM. Unpaired Student's $t$ test was performed between cytokine and shaminjected mice data. $* P<0.0005$ compared with sham-injected mice. 

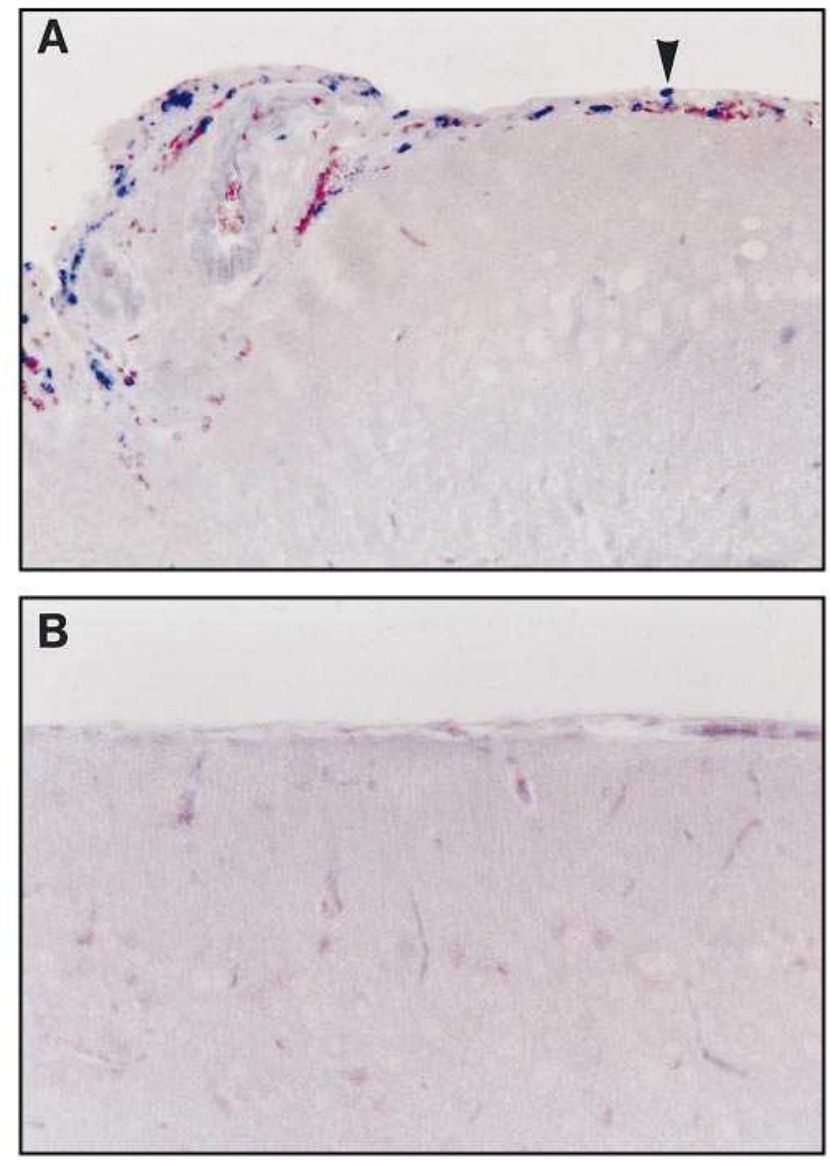

Figure 2. Localization of neutrophil exudates in brain tissue sections after meningitis. Brain tissue was harvested from mice $4 \mathrm{~h}$ after lumbar inoculation of cytokines or sham injection. Sections were stained for PMNs. (A) In cytokine-treated mice PMNs, identified by dark blue stained granules (arrowhead), accumulated selectively in meningeal and submeningeal areas with no PMNs present in the brain parenchyma. (B) There were no detectable PMNs in neural tissue of sham-injected animals. $\times 194$.

cytospun slides. Total blood leukocytes were determined by Coulter count of samples (Coulter Electronics, Hialeah, FL) after lysis of red blood cells. Differential leukocyte counts on blood samples were determined on blood smears stained with Wright's Giemsa.

Evaluation of BBB permeability. Fluorescence intensity of CSF and blood samples was measured in a microtiter plate fluorometer (Pandex, Baxter Healthcare, Chicago, IL). The BBB permeability index was expressed as $\mathrm{I}_{\text {csf }}$ (fluorescence intensity per $\mu$ l CSF sample) divided by $I_{\text {blood }}$ (fluorescence intensity per $\mu$ l blood sample), i.e. $\left(I_{\text {csf }} /\right.$ $\mathrm{I}_{\text {blood }}$ ), a method modified from that described by Kurose et al. (21).

\section{Histology}

Brain tissue was fixed in $4 \%$ paraformaldehyde and paraffin-embedded. 4- $\mu \mathrm{m}$ sections were cut and subjected to the dichloroacetate esterase reaction, as described by Yam et al. (22), which allows identification of extravasated PMNs. The specific esterase also identifies mast cells, but brains harvested from sham-injected animals had no specific esterase stain.

\section{Statistics}

All parameters in this study are expressed as mean \pm SEM. Unpaired Student's $t$ tests were performed for unpaired data and $P$ values $<0.05$ were considered significant.

\section{Results}

Time course of neutrophil and mononuclear cell accumulation in the CSF. Doses of human recombinant cytokines IL-1 $\beta$ (1.25 U/gram body weight) (hIL-1 $\beta$ ) and TNF $\alpha$ (4 U/gram body weight) (hTNF $\alpha$ ) were used in the range that has been shown previously to be effective in eliciting CSF leukocyte influx in rats (17). In wild-type mice, inoculation of cytokines via lumbar puncture at vertebrate level L1 or L2 resulted in leukocyte influx in the CSF as early as $2.5 \mathrm{~h}(200-500$ cells/ $\mu \mathrm{l})$. CSF leukocyte counts increased sharply by $4 \mathrm{~h}$ to $12,000-15,000$ cells/ $\mu \mathrm{l}$, peaked at $6 \mathrm{~h}$, and by $24 \mathrm{~h}$ dropped to $<1,000 \mathrm{cells} / \mu \mathrm{l}$ (Fig. 1). Neutrophils (PMNs) composed the majority of leukocytes at early time points, $2.5-6 \mathrm{~h}(78-95 \%)$, whereas at $8 \mathrm{~h}$ mononuclear cells represented on average $57 \%$ of the leukocyte population (Fig. 1). Lower doses of hIL-1 $\beta$ in combination with hTNF $\alpha$ were found to be less effective in eliciting leukocytes into the CSF at the $4 \mathrm{~h}$ time point. Murine IL-1 $\beta$ produced a dose-dependent white blood cell influx into the CSF but had a dramatically lower potency than human IL-1 $\beta$. The peak response $(5,650$ cells/ $\mu \mathrm{l})$ was observed at $25 \mathrm{U} / \mathrm{gram}$ which is a concentration 20-fold higher than the dose of hIL-1 $\beta$ used to elicit on average 14,000 cells/ $\mu$ l (data not shown).

Cytokine-induced PMN accumulation in the CSF was due primarily to meningeal inflammation. PMN exudates in brain tissue harvested $4 \mathrm{~h}$ after inoculation were identified by a specific esterase stain and were abundant selectively around meningeal vessels with none detected in the parenchyma. In shaminjected mice, no PMNs were observed (Fig. 2). In addition, at $24 \mathrm{~h}$, minimal PMN exudates were detected in brain sections (data not shown), which is consistent with the significant decline in CSF leukocyte accumulation at this time point (Fig. 1).

Cytokine-induced meningitis was not fatal. Mice $(n=6)$ survived up to $6 \mathrm{~d}$ after induction of the disease, were active, and showed no clinical signs of nervous system injury such as ataxia, tremor of the head and extremities, myoclonic jerks, or paralysis.

CSF leukocyte accumulation and $B B B$ permeability in mice deficient in P-selectin and mice doubly deficient in P-and E-selectins. Cytokine-induced meningitis was examined in P-selectindeficient mice and wild-type mates (5) and mice doubly deficient in P- and E-selectins and wild-type mates (6) at multiple time points. Since both sets of wild-type mice displayed similar responses to meningitis, the data for these animals were combined. In P-selectin-deficient mice, a significant reduction in leukocyte recruitment into the CSF at 4 and $6 \mathrm{~h}$, with recovery to wild-type levels by $8 \mathrm{~h}$, was observed. P-and E-selectin doubly deficient mice had a striking deficit in CSF leukocyte recruitment compared with both wild-type mice and mice deficient in P-selectin alone. At $4 \mathrm{~h}$, leukocyte accumulation was similar to that observed in sham-injected mice and at $6 \mathrm{~h}$, the peak of neutrophil influx, was $96 \%$ inhibited compared with wild-type animals (Fig. $3 A$ ). These data are even more meaningful given that $\mathrm{P}-$, and $\mathrm{P}$ - and E-selectin-deficient mice had $\sim 2$.9- and 8.5-fold higher numbers of blood PMNs, respectively, compared with wild-type mice $4-6 \mathrm{~h}$ after cytokine inoculation (data not shown), consistent with the neutrophilia reported in these animals $(5,6)$. At $8 \mathrm{~h}$, CSF leukocyte accumulation in doubly deficient mice was $32 \%$ of wild-type levels. At $24 \mathrm{~h}$, total leukocyte counts in all three genotypes had dropped significantly with no observable difference between P-selectin-deficient and wild-type mice but a threefold 

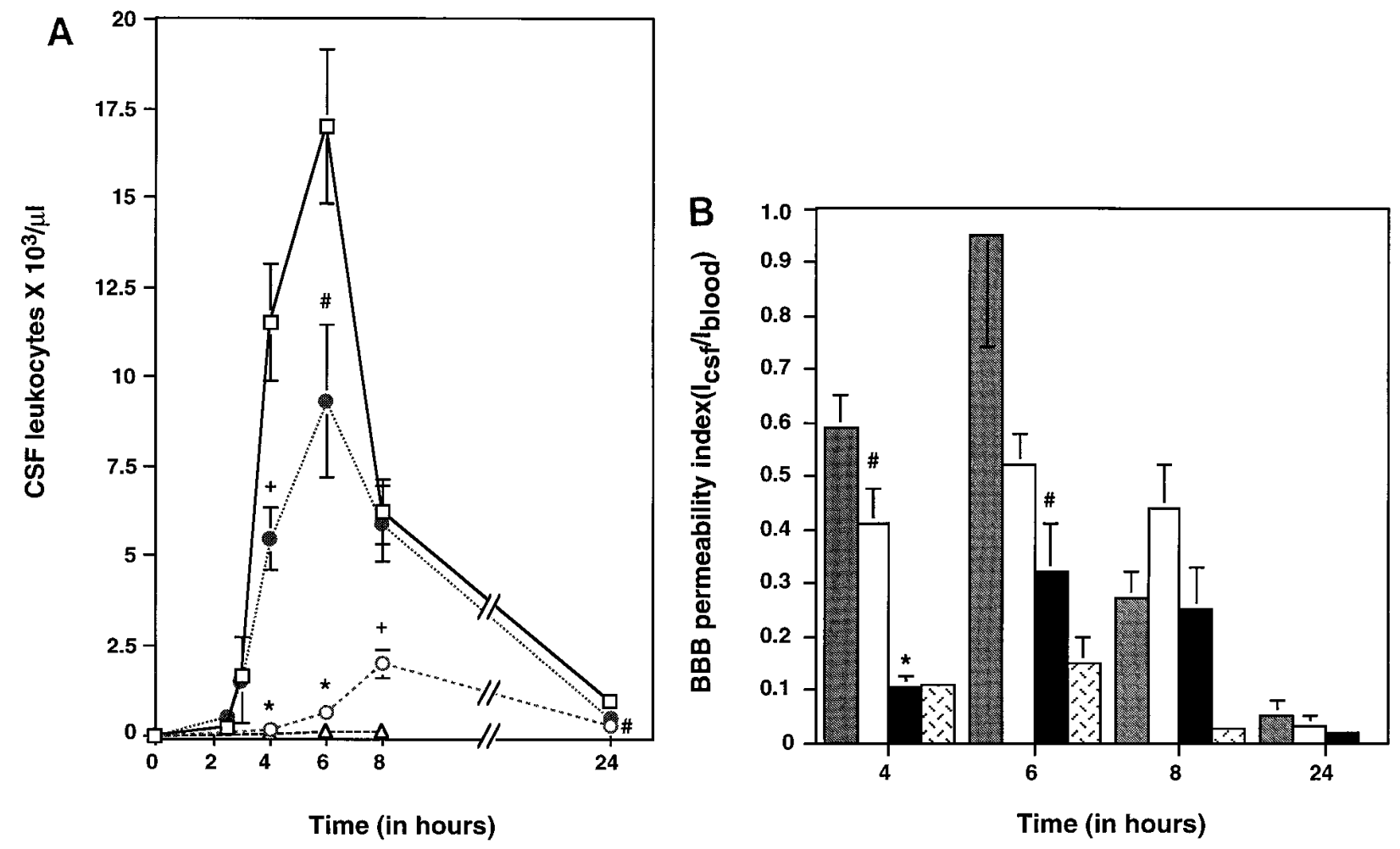

Figure 3. CSF leukocyte accumulation and BBB permeability in selectin-deficient mice. P-selectin-null, P- and E-selectin-null, and wild-type mice were injected with cytokines and wild-type mice were sham-injected. The 4-, 6-, and 8-h time points represent a minimum of eight animals of each genotype and the 24-h time point represents four mice of each genotype. Total leukocyte counts in CSF and blood samples were determined and the BBB index was calculated. (A) P-selectin-deficient mice (closed circles) had significantly fewer CSF leukocytes at 4 and $6 \mathrm{~h}$ compared with wild-type mice (open squares). P- and E-selectin-deficient mice (open circles) had leukocyte influx similar to sham-injected mice (open triangles) at $4 \mathrm{~h}$ and continued to exhibit significantly reduced influx at 6,8 , and $24 \mathrm{~h}$. The percentage of mononuclear cells and neutrophils in selectin-deficient mice at $8 \mathrm{~h}$ was similar to that in wild-type animals (data not shown). (B) The BBB permeability index was significantly higher in wild-type mice (gray bar) compared with sham-injected mice (hatched bar) at 4,6 , and $8 \mathrm{~h}$ after cytokine inoculation $(P<0.05)$. BBB permeability was inhibited in P-selectin-deficient mice (white bar) at 4 and $6 \mathrm{~h}$ and was further attenuated in P-and E-selectin-deficient mice (black bar) at these two time points. Unpaired Student's $t$ tests were performed between wild-type and selectin-deficient mice data. $* P<$ $0.00001 ;{ }^{+} P<0.005 ;{ }^{\#} P<0.05$.

reduction in P- and E-selectin-deficient compared with wildtype mice.

CSF traversal of systemically injected FITC-conjugated BSA was assessed in the above animals and served as an index of $\mathrm{BBB}$ permeability. The BBB index was calculated as the ratio of fluorescence intensity in CSF sample $\left(\mathrm{I}_{\mathrm{csf}}\right)$ versus that measured in peripheral blood $\left(\mathrm{I}_{\text {blood }}\right)$, a method previously used to assess vascular permeability (21). The extent of BSA penetration into the CSF was significantly lower in the P-selectin-deficient mice compared with wild-type animals at $4 \mathrm{~h}$ and remained so at $6 \mathrm{~h}$ after cytokine inoculation although this was not statistically significant. BBB permeability in $\mathrm{P}$ - and E-selectin deficient mice was reduced further compared with P-selectin-null animals at $4 \mathrm{~h}$ and was indistinguishable from that observed in shaminjected animals at this time point. At $6 \mathrm{~h}$, the BBB index was one-third that of the wild-type mice. $\mathrm{BBB}$ permeability was reversible at 8 and $24 \mathrm{~h}$, and there was no significant difference between wild-type and selectin-deficient mice (Fig. $3 B$ ).

\section{Discussion}

We describe a cytokine-induced acute meningitis model which results in significant leukocyte accumulation and BBB perme- ability in mice and demonstrate a vital role for endothelial selectins in leukocyte extravasation across the meningeal $\mathrm{BBB}$ and in CSF protein accumulation in this model. We directly inoculated the CSF with IL-1 $\beta$ and TNF $\alpha$ to induce meningitis since these cytokines are detected in the CSF of patients with bacterial meningitis caused by gram-negative and gram-positive organisms $(16,23-25)$ and represent common host mediators of diverse effects in this disease. Simultaneous administration of these two cytokines leads to inflammatory cell influx and BBB injury $(17,19)$ and functional blocking of these cytokines with antibodies results in inhibition of meningeal inflammation (19). Quagliarello et al. (17) also present evidence that hIL-1 $\beta$ is independently a potent inducer of leukocyte pleocytosis and BBB injury in rats, that hTNF $\alpha$ alone has minimal effects, and that the combination of these cytokines elicits a synergistic response. The local production and secretion of IL-1 and TNF, potentially produced by several cell types within the CNS including monocytes/macrophages lining the leptomeninges, microglial cells, astrocytes, and the vascular endothelium (26-28), is known to be induced by subcapsular bacterial surface components $(8,29)$. These inflammatory cytokines stimulate P- and E-selectin expression in murine leptomeningeal vessels in vivo (3) and on murine cerebral endothelial cells in vitro (30). 
Studies of human meningitis have documented that adjuncts to antibiotic therapy that can blunt the inflammatory response can reduce mortality. Strategies have included blocking cytokine or arachidonate generation or attenuating inflammatory cell influx $(10,11)$. Blocking inflammatory cell influx in conjunction with administering antibiotics has several advantages in treating meningitis. First, bactericidal antibiotics administered to eradicate bacteria often initially worsen the clinical picture of meningitis since bacteria lysis leads to release of proinflammatory cell fragments into the CSF which signal further leukocyte influx. Second, infiltrating blood leukocytes can be carriers of bacteria into the CSF. And third, potential inhibitors given intravenously would not be required to cross the BBB since their target, the leukocyte or endothelium, resides within the vascular compartment. Inhibiting leukocyte influx should not adversely affect the course of infection since leukocyte themselves do not play a significant role in attenuating the bacterial infection due to the very limited humoral immune defenses (both complement and immunoglobulin) in the $\operatorname{CSF}(8,29)$.

The selectins and members of the IgG superfamily, ICAM-1 and VCAM-1, are part of the endothelial repertoire of leukocyte adhesion molecules which support leukocyte recruitment. The selectins support rolling of unactivated leukocytes on the endothelium and recent evidence suggests that engagement of $\mathrm{P}$ - and E-selectins also signals the upregulation of the $\beta_{2}$ integrin Mac-1 which promotes firm adhesion of leukocytes to the endothelium $(31,32)$. Our studies showing a near complete inhibition of leukocyte influx and BBB permeability in P-and E-selectin-deficient mice suggest that the endothelial selectins are the primary leukocyte adhesion receptors responsible for leukocyte recruitment to meningeal endothelium. The fact that the effect seen in mice doubly deficient in P- and E-selectins exceeds by far that seen in P-selectin-deficient mice indicates that endothelial selectins act cooperatively in these processes. Although endothelial selectin synergy in leukocyte recruitment has been described previously in a thioglycollate-induced peritonitis model, the effects of endothelial selectin ablation (6) or inhibition (7) on leukocyte recruitment in the latter model were not as dramatic (20\% of wild-type) as those observed in our study ( $4 \%$ of wild-type). In addition, selectin synergy was observed only $6-8 \mathrm{~h}$ after challenge and not at earlier time points $(6,7)$. These differences suggest that the cooperation of endothelial selectins in leukocyte recruitment is more important in some tissues than in others and is likely dependent on the tissue expression of these molecules and the combination of inflammatory mediators present. In the cytokine-induced meningitis model, the incomplete inhibition of leukocyte recruitment at $8 \mathrm{~h}$ in $\mathrm{P}$ - and E-selectin-deficient mice suggests that other leukocyte adhesion receptors may be important at this time point. A role for the leukocyte selectin, L-selectin, in leukocyte recruitment in an experimental meningitis model in rabbits has been previously suggested. The polysaccharide fucoidin, an inhibitor of L-selectin as well as P-selectin, was shown to ablate leukocyte and plasma protein accumulation in the CSF at $8 \mathrm{~h}$ after inoculation of heat-killed Streptococcus pneumoniae (33) although its effects at earlier time points were not reported.

Several studies have suggested a direct link between leukocyte extravasation into the subarachnoid space and perturbation of the BBB. CSF protein accumulation is an index of the functional alteration of the BBB localized to the cerebral microvascular endothelium, whose injury is responsible for va- sogenic brain edema observed in many forms of meningitis (34). Importantly, a significant protection in BBB permeability (70-100\%) in P- and E-selectin-deficient mice was apparent up to $6 \mathrm{~h}$ after induction of the disease. These effects were more pronounced than those seen with $\beta_{2}$ integrin antibodies in infectious rabbit meningitis (55-65\% inhibition) (11), although a direct comparison of ours and the latter results cannot be made until antagonists to these molecules are tested in the same model. Our study also suggests that the cytokines alone do not play a significant role in promoting BBB injury since near complete inhibition of leukocyte extravasation in $\mathrm{P}$ - and E-selectin-deficient mice $4 \mathrm{~h}$ after cytokine-induced meningitis was associated with a complete protection of BBB permeability in these animals.

In conclusion, the development of a meningitis model in adult mice allows the examination of various genetically engineered mouse strains deficient in other adhesion molecules and provides an efficacious way of testing potential inhibitors of leukocyte influx. Although characterization of mouse strains was not the focus of this study, we would like to alert readers that as in many in vivo models of inflammation, some strains of mice may respond less well than others. Our studies suggest that the endothelial selectins together play a key role in the recruitment of leukocytes across the $\mathrm{BBB}$ and in associated BBB injury in response to acute inflammatory stimuli. Previous antagonists to selectins such as Sialyl $\mathrm{Le}^{\mathrm{x}}$ or monoclonal antibodies have proven effective in blocking leukocyte influx in vivo $(2,35)$. Blocking selectins can theoretically have several advantages over blocking integrins or members of the IgG superfamily. First, selectins are expressed within the vasculature, therefore inhibitors against selectins would potentially have fewer side effects compared with those against more widely expressed leukocyte adhesion molecules. Second, targeting leukocyte rolling will block the earliest known leukocyte-endothelial interaction. Third, unlike $\beta_{2}$ antibodies which lead to a greater incidence of septic complications in Escherichia coli-induced peritonitis and development of subcutaneous Staphylococcus aureus abscesses (36), blocking of P-selectin does not appear to increase the risk of bacterial infections (37). If cytokine-induced meningitis mimics the processes involved in leukocyte recruitment in human meningitis, antagonists to these selectins in partnership with antibiotics could have beneficial effects in meningitis by limiting the deleterious effects of leukocyte recruitment.

\section{Acknowledgments}

We thank Dr. Matthew Frosch (Brigham and Women's Hospital) for helpful discussions and critical reading of the manuscript and Dr. Dianne Griffin (Johns Hopkins University, Baltimore, MD) for kindly instructing us in retrieval of CSF from mice.

This research was supported by National Institutes of Health research grants NS33296 (T.N. Mayadas), HL-41002 and HL-53756 (D.D. Wagner), PO1HL41484, and Howard Hughes Medical Institute (R.O. Hynes); a postdoctoral fellowship from the National Multiple Sclerosis Society (T. Tang); and a fellowship by the Medical Research Council of Canada (P.S. Frenette). R.O. Hynes is an investigator of Howard Hughes Medical Institute.

\section{References}

1. Springer, T.A. 1994. Traffic signals for lymphocyte recirculation and leukocyte emigration: the multistep paradigm. Cell. 76:301-314. 
2. Carlos, T.M., and J.M. Harlan. 1994. Leukocyte-endothelial adhesion molecules. Blood. 84:2068-2101.

3. Gotsch, U., U. Jager, M. Dominis, and D. Vestweber. 1994. Expression of P-selectin on endothelial cells is upregulated by LPS and TNF-alpha in vivo. Cell Adhesion and Communication. 2:7-14.

4. Weller, A., S. Isenmann, and D. Vestweber. 1992. Cloning of the mouse endothelial selectins: expression of both $\mathrm{E}$ - and P-selectin is inducible by tumor necrosis factor $\alpha . J$. Biol. Chem. 267:15176-15183.

5. Mayadas, T.N., R.C. Johnson, H. Rayburn, R.O. Hynes, and D.D. Wagner. 1993. Leukocyte rolling and extravasation are severely compromised in P selectin-deficient mice. Cell. 74:541-554.

6. Frenette, P.S., T.N. Mayadas, H. Rayburn, R.O. Hynes, and D.D. Wagner. 1996. Susceptibility to infection and altered hematopoiesis in mice deficient in both P- and E-selectin. Cell. 84:563-574.

7. Labow, M.A., C.R. Norton, J.M. Rumberger, K.M. Lombard-Gillooly, D.J. Shuster, J. Hubbard, R. Bertko, P.A. Knaack, R.W. Terry, M.L. Harbison, et al. 1994. Characterization of E-selectin-deficient mice: demonstration of overlapping function of the endothelial selectins. Immunity. 1:709-720.

8. Quagliarello, V.J., and W.M. Scheld. 1993. New perspectives on bacterial meningitis. Clin. Infect. Dis. 17:603-610.

9. Tuomanen, E. 1992. Adjunctive therapy of experimental meningitis: agents other than steroids. In Bacterial Meningitis. Antibiotic Chemotherapy. H. Schonfeld and H. Helwig, editors. Karger, Basel. 184-191.

10. Tuomanen, E. 1994. Modulation of inflammation in bacterial meningitis. Isr. J. Med. Sci. 30:339-341.

11. Tuomanen, E., K. Saukkonen, S. Sande, C. Cioffe, and S.D. Wright. 1989. Reduction of inflammation, tissue damage, and mortality in bacterial meningitis in rabbits treated with monoclonal antibodies against adhesion-promoting receptors of leukocytes. J. Exp. Med. 170:959-968.

12. Sáez-Llorens, X., H.S. Jafari, C. Severien, F. Parras, K.D. Olsen, E.J. Hansen, I.I. Singer, and G.H. McCracken, Jr. 1991. Enhanced attenuation of meningeal inflammation and brain edema by concomitant administration of anti-CD18 monoclonal antibodies and dexamethasone in experimental Haemophilus meningitis. J. Clin. Invest. 88:2003-2011.

13. Tan, T.Q., C. Wayne Smith, E.P. Hawkins, E.O. Mason, Jr., and S.L. Kaplan. 1995. Hematogenous bacterial meningitis in an intercellular adhesion molecule-1-deficient infant mouse model. J. Infect. Dis. 171:342-349.

14. Rodewald, A.K., A.B. Onderdonk, H.B. Warren, and D.L. Kasper. 1992. Neonatal mouse model of group B streptococcal infection. J. Infect. Dis. 166:635-639.

15. Tsai, Y.H., E.B. Williams, R.S. Hirth, and K.E. Price. 1975. Pneumococcal meningitis: therapeutic studies in mice. Chemotherapy. 21:342-357.

16. Leist, T.P., K. Frei, S. Kam-Hansen, R.M. Zinkernagel, and A. Fontana 1988. Tumor necrosis factor alpha in cerebrospinal fluid during bacterial, but not viral, meningitis. Evaluation in murine model infections and in patients. $J$. Exp. Med. 167:1743-1748.

17. Quagliarello, V.J., B.Wispelwey, W.J. Long, and W.M. Scheld. 1991. Recombinant human interleukin-1 induces meningitis and blood-brain barrier injury in the rat. $J$. Clin. Invest. 87:1360-1366.

18. Mustafa, M.M., O. Ramilo, K.D. Olsen, P.S. Franklin, E.J. Hansen, B. Beutler, and G.H. McCracken, Jr. 1989. Tumor necrosis factor in mediating experimental Haemophilus influenzae type B meningitis. J. Clin. Invest. 84:12531259.

19. Ramilo, O., X. Saez-Llorens, J. Mertsola, H. Jafari, K.D. Olsen, E.J. Hansen, M. Yoshinaga, S. Ohkawara, H. Nariuchi, and G.H. McCraken, Jr. 1990. Tumor necrosis factor $\alpha /$ cachectin and interleukin $1 \beta$ initiate meningeal inflammation. J. Exp. Med. 172:497-507.
20. Griffin, D.E. 1981. Immunoglobulins in the cerebrospinal fluid: changes during acute viral encephalitis in mice. J. Immunol. 126:27-31.

21. Kurose, I., T. Yamada, R. Wolf, and D.N. Granger. 1994. P-selectindependent leukocyte recruitment and intestinal mucosa injury induced by lactoferrin. J. Leukocyte Biol. 55:771-777.

22. Yam, L.T., C.Y. Li, and W.H. Crosby. 1971. Cytochemical identification of monocytes and granulocytes. Am. J. Clin. Pathol. 55:283-290.

23. McCracken, G.H., Jr., M.M. Mustafa, O. Ramilo, K.D. Olsen, and R.C. Risser. 1989. Cerebrospinal fluid interleukin-1 $\beta$ and tumor necrosis factor concentrations and outcome from neonatal gram-negative enteric bacillary meningitis. Ped. Infect. Dis. J. 8:155-159.

24. Waage, A., A. Halstensen, R. Shalaby, P. Brandtzaeg, P. Kierulf, and T. Espevik. 1989. Local production of tumor necrosis factor $\alpha$, interleukin 1, and interleukin 6 in meningococcal meningitis. Relations to the inflammatory response. J. Exp. Med. 170:1859-1867.

25. Mustafa, M.M., M.H. Lebel, O. Ramilo, K.D. Olsen, J.S. Reisch, B. Beutler, and G.H. McCracken, Jr. 1989. Correlation of interleukin-1 $\beta$ and cachectin concentrations in cerebrospinal fluid and outcome from bacterial meningitis. J. Pediatr. 115:208-213.

26. Dinarello, C.A. 1988. Biology of interleukin-1. FASEB (Fed. Am. Soc. Exp. Biol.) J. 2:108-115.

27. Robbins, D.S., Y. Shivazi, B.E. Drysdale, A. Lieberman, H.S. Shin, and M.L. Shin. 1987. Production of cytotoxic factor for oligodendrocytes by stimulated astrocytes. J. Immunol. 139:2593-2597.

28. Frei, K., C. Siepl, P. Groscurth, S. Bodmer, C. Schwerdel, and A. Fontana. 1987. Antigen presentation and tumor cytotoxicity by interferon- $\gamma$-treated microglial cells. Eur. J. Immunol. 17:1271-1278.

29. Tuomanen, E., and A. Baruch. 1989. New antibodies as adjunctive therapies for gram-positive bacterial meningitis. Ped. Infect. Dis. J. 8:923-928.

30. Barkalow, F.J., M.J. Goodman, and T.N. Mayadas. 1996. Cultured murine cerebral microvascular endothelial cells contain von Willebrand factor positive Weibel-Palade bodies and support rapid cytokine-induced neutrophil adhesion. Microcirculation. 3:19-28.

31. Lo, S.K., S. Lee, R.A. Ramos, R. Lobb, M. Rosa, G. Chi-Rosso, and S.D. Wright. 1991. Endothelial-leukocyte adhesion molecule-1 stimulates the adhesive activity of leukocyte integrin CR3 (CD11b/CD18, Mac-1, $\alpha \mathrm{m} \beta 2$ ) on human neutrophils. J. Exp. Med. 173:1493-1500.

32. Cooper, D., C.M. Butcher, M.C. Berndt, and M.A. Vadas. 1994. P-selectin interacts with a $\beta 2$-integrin to enhance phagocytosis. J. Immunol. 153:31993209.

33. Granert, C., J. Raud, X. Xie, L. Lindquist, and L. Lindbom. 1994. Inhibition of leukocyte rolling with polysaccharide fucoidin prevents pleocytosis in experimental meningitis in the rabbit. J. Clin. Invest. 93:929-936.

34. Scheld, W.M., V.J. Quagliarello, and A.J. Lesse. 1987. Selected aspects of the pathogenesis and pathophysiology of bacterial meningitis. In Bacterial Meningitis. J.D. Williams and J. Burnie, editors. Academic Press, Boston. 1-21.

35. Mulligan, M.S., J.C. Paulson, S. De Frees, Z.-L. Zheng, J.B. Lowe, and P.A. Ward. 1993. Protective effects of oligosaccharides in P-selectin-dependent lung injury. Nature (Lond.). 364:149-151.

36. Sharar, S.R., R.K. Winn, C.E. Murry, J.M. Harlan, and C.L. Rice. 1991. A CD18 monoclonal antibody increases the incidence and severity of subcutaneous abscess formation after high-dose Staphylococcus aureus injection in rabbits. Surgery (St. Louis). 110:213-220.

37. Sharar, S.R., S.S. Sasaki, L.C. Flaherty, J.C. Paulson, J.M. Harlan, and R.K. Winn. 1993. P-selectin blockade does not impair leukocyte host defense against bacterial peritonitis and soft tissue infection in rabbits. J. Immunol. 151: 4982-4988. 